\title{
Miocene to recent chemical weathering in the Himalaya inferred from the stable Li-isotopes
}

SAJID ALI

Birbal Sahni Institute of Paleosciences

Presenting Author: sajidali7861@gmail.com

Miocene to recent chemical weathering in the Himalaya inferred from the stable Li-isotopes

Sajid Ali ${ }^{1,2, *}$, Ed Hathorne ${ }^{2}$, Martin Frank ${ }^{2}$

${ }^{1}$ Birbal Sahni Institute of Palaeosciences Lucknow, India

${ }^{2}$ GEOMAR Helmholtz Centre for Ocean Research Kiel, Germany

(sajidali@bsip.res.in)

The interplay between tectonic exhumation, climate, atmospheric $\mathrm{CO}_{2}$ and continental erosion and weathering is crucial to understand the mechanism that forced Cenozoic global cooling. However, long-term silicate weathering records are poorly constrained in the Himalayan belts during Late Cenozoic period. We present radiogenic $\mathrm{Sr}, \mathrm{Nd}$ and stable $\mathrm{Li}$ isotope compositions measured on Himalayan foreland basin clays to delineate the sources of the clays and silicate weathering history over the past $20 \mathrm{Myr}$. Our Sr-Nd isotope records show that the foreland clays were mainly supplied from the Higher Himalayas between 20 and 9 Myr ago. Thereafter the source shifted to Lesser Himalayan sources to switch back to High Himalayan dominance 5 Myr ago. Our clay mineral assemblages and $\mathrm{Li}$ isotope results show a strong positive excursion between 14 and $8 \mathrm{Ma}$ ago, suggesting weak chemical weathering possibly linked with reduced atmospheric $\mathrm{CO}_{2}$ and global cooling with the development of dry climate during the Middle Miocene Climate Transition (MMCT). On the other hand, a high Kaolinite/illite+chlorite and negative $\mathrm{Li}$ isotope excursion indicate strong chemical weathering $\sim 8 \mathrm{Myr}$ coincide with the Late Miocene global cooling and stronger seasonality. 